\title{
Quality Improvement, Risk Management, and Patient Education: Tools to Reduce Medication Error
}

Upon completion of this continuing education program, participants will be able to:

1. Explain the purpose of accreditation and accreditation standards and their limitation.

2. Differentiate quality, consistency, and safety.

3. Discuss tools for assuring quality and predicting failure within systems.

4. Describe a process for conducting a root-cause analysis.

5. Discuss actions pharmacy and pharmacists can take to reduce medication errors.

6. List steps that patients can take to help prevent medication errors.

KEYWORDS: Patient education, medication errors, quality improvement, root-cause

J Managed Care Pharm 2001: 156-63

\section{Author}

LINDA L. NORTON, Pharm.D., is Associate Professor, Department of Pharmacy Practice, and Director, Postgraduate Professional Education, University of the Pacific School of Pharmacy and Health Sciences, Stockton, CA.

AUTHOR CORRESPONDENCE: Linda L. N orton, Pharm.D., Director, Postgraduate Professional Education, U niversity of the Pacific School of Pharmacy and Health Sciences, 751 Brookside Road, Stockton, CA 95211; Tel: 209-946-2412; Fax: 209-946-3180; E-mail: Inorton@uop.edu.

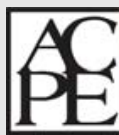

The Academy of M anaged Care Pharmacy is approved by the American Council on Pharmaceutical Education as a provider of continuing pharmaceutical education. Individuals may obtain up to 1 contact hour of credit or 0.10 Continuing Education U nit (CEU). The ACPE number is 233-000-01-002-H04. Certificates will be mailed within eight weeks to participants who successfully complete the CE exam and achieve a score of $70 \%$ or more and submit the exam to AM CP prior to April 30, 2002. Learning objectives and test questions follow on page 164.

Copyright@ 2001 Academy of Managed Care Pharmacy, Inc. All rights reserved. by Linda L. N orton

$\mathrm{M}$

edical and medication errors are serious problems in the United States and throughout the world. These errors have a huge economic impact on health care patients and payors alike: the cost of medical and medication errors in the United States has been estimated to be nearly $\$ 30$ billion per year and may be nearing $\$ 40$ billion per year..$^{1-3}$ And the costs of these errors are counted in more than just dollars: There are estimates that between 44,000 and 98,000 Americans die each year as a result of medical errors. ${ }^{1,2,4}$ The exact number of deaths attributable to medication and prescription errors, such as prescriptions used incorrectly and problems with over-the-counter medications, is not known. But we have enough evidence to know that the problem is large and warrants attention not just from the federal government but also from patients, health care providers, and the organizations that manage care. For example, estimates from the federal government place the number of deaths attributable to preventable medication errors at 7,000 per year. ${ }^{1}$ A 1977 article reported that $50 \%$ of all prescriptions are used incorrectly. ${ }^{5}$ And one 1995 article reported that about $10 \%$ of hospital admissions were related to problems from medication use. ${ }^{6}$

Medical errors are health system issues, and solutions to the problems must also be system-based. ${ }^{7}$ One of the factors that makes the issue of medication errors so problematic is that they too are system errors, but the system is extremely diverse. These errors and adverse events occur in all types of patients, in all types of settings; their proximal causes can be associated with physicians, pharmacists, nurses, caregivers, or patients. In fact, a study of 1,000 nonhospitalized patients showed that 42 patients experienced side effects of medication use, with 23 of the 42 patients $(54 \%)$ experiencing a preventable adverse event. ${ }^{8}$ Hearing these statistics on the news and reading them in articles and continuing education programs can help health care providers define the significance and magnitude of the problem, but the statistics alone do not point to specific solutions or provide tools for change.

Terms such as quality, safety, consistency, and others have precise definitions. These are shown in Table 1, page 157.

\section{Accreditation}

Accreditation cannot guarantee patient safety. Accreditation is, in most cases, a statement from an accrediting body such as the National Committee for Quality Assurance (NCQA) or the Joint Commission on Accreditation of Healthcare Organizations (JCAHO) that the product, service, or organization meets or 
Definitions

- Quality: "superiority in kind."

- Consistency: the "harmony of conduct or profession."

- Safety: "to protect against failure, breakage, or accident" (requires doing it right and doing it every time)

- Error-free: avoidance of an act or accident that "fails to achieve what should be done."

- Accreditation: "conferring approval or recognition for conforming to, or meeting standards."

Source: M erriam-W ebster Collegiate Dictionary, available online at www.mw.com/cgi-bin/dictionary.

exceeds selected requirements. For example, NCQA accreditation can provide a strong statement on the quality of an organization, at least when quality is judged on standards such as access to care and service, qualifications of providers, maintenance of health, early detection of illnesses, and care during both acute and chronic illnesses. While these requirements are quite rigorous, and may be indications of quality, they are not guarantees of safety from medical error. Error-free care is safe, consistent, quality care that is comprehensive; it is care that is done right, and it is a system characteristic.

\section{What Managed Care Organizations Should Expect from Providers}

When a managed care organization (MCO) submits a request for proposal (RFP) to providers of health care, what are its expectations? If an MCO is accredited by NCQA, its members are assured that the organization has met certain standards. If the MCO contracts with a medical facility that has been accredited by JCAHO, it can be assured of compliance with preset standards. But what assurances are there when an MCO contracts with a chain of pharmacies, or laboratories, or a physicians' group? Are there hallmarks for quality, consistency, safety, and error-free care for these groups? Each of these groups meets specific requirements for licensure, but licensure is usually only a statement that the licensee has the minimum qualifications required to practicethat is, the provider or facility has passed an examination or inspections and continues to maintain the license. A universal statement of excellence in care for all of these groups does not exist. However, there are indicators of a company's commitment to improving care by decreasing the risk of failure or error and improving the quality of care through the provision of consistently error-free care.

In the absence of a universal statement of excellence in care, an RFP that asks for evidence to support positive answers to the following questions will help MCOs ensure that high standards are maintained. These standards for improving the quality of care and patient safety and decreasing risk from system failure and error should be priorities of the responding organization:
- Can the organization and its contract companies predict and prevent most failures within the medication-use system and the larger health care system?

- Can the organization and its contract companies identify the root cause(s) of failures in the medication-use system and the larger health care system?

- Does the organization offer training on continuous risk management to health-service providers with whom it contracts?

- Do the companies that contract with the organization work with the MCO and others to provide continuous risk management?

In aerospace, aviation, and other industries with very low tolerances for errors or systems failures, the answer to these questions is yes..$^{9,10}$ For many of the organizations that provide health care coverage in the United States the answer to these questions is no. This is a profound statement on the condition of risk management, quality improvement, and medicationerror reduction in the United States.

\section{Eurror-Prevention Programs}

Error-prevention programs in industry have been successfully operating for decades, identifying areas where potential problems or system failures may occur and developing alternatives with lower error or failure potential. In some cases, error or failure prevention cannot be guaranteed and back-up systems have been developed. In health care, error prevention is still in its infancy, but often tools and techniques that have been effective in one environment can be successfully transferred to another.

Risk-management, quality-improvement, and error-reduction tools and processes that were developed for use in the military have been quite helpful in different areas that have similar needs. Techniques that have been used by commercial airlines and the aerospace industry and at the National Aeronautics and Space Administration (NASA) have been suggested as reasonable options for error reduction in health care. ${ }^{11}$ In both the space program and health care, risk is managed so that potential problems can be identified, the chances for successful projects or procedures can be increased, project failures or errors can be averted, and resources can be used efficiently. The transfer of processes and techniques seems particularly promising when the environments are compared and the criteria for a successful risk-management plan are reviewed. Risk can be managed in a disciplined environment that facilitates continual assessment of risk including potential problems, failures, or errors; prioritization of risk; implementation of strategies for mitigating risk; and research to increase the understanding of risk. ${ }^{12}$ Fortunately, most health care settings currently meet, or can meet, these requirements.

Reducing risk and medication errors requires resources and continuous commitment to the effort. It also requires system-based quality-improvement and risk-management tools. Many of these tools are available, making the process of selecting the appropriate 


\begin{tabular}{l|c|c}
\hline \multicolumn{3}{c}{ Abbreviated Risk Matrix } \\
\hline Event Severity & \multicolumn{2}{|c}{ Likelihood of Occurrence } \\
\hline & Probable & Remote \\
\hline Devastating & High & Moderate \\
\hline Negligible & Moderate & Low \\
\hline
\end{tabular}

one for a given environment somewhat confusing. Searching for quality and safety tools on the Internet yields W eb pages on such topics as ISO 9000, which provides a framework for quality assurance; ISO 14000, which provides a framework for environmental management; PDCA, an abbreviation of W. Edwards Deming's Plan, Do, Check, Act study cycle; and FOCUS-PDCA, systematic methods or cycles for process improvement incorporating PDCA.

But, as previously mentioned, error- and failure-reduction techniques that have been used at NASA may be good options for error reduction in health care. Just two "mouse clicks" away from the PDCA W eb page is the O ffice of Safety and Assurance Technologies (OSAT) at the NASA Glenn Research Center. ${ }^{13}$ At the NASA Risk Management Office (RMO) Web page, documents such as NPG 7120.5A-Program and Project Management Processes and Requirements can be downloaded, and a Continuous Risk Management (CRM) Guidebook can be located. Amid comics featuring two little "Martians," there are risk-management cycles with in-depth information and links to $W$ eb pages with specific require ments for NASA projects. Here, much like medication-error prevention in health care, the key to succeeding and meeting many of the requirements is the use of an effective system to assist in predicting and then preventing mission-critical failures. One of the NASA pages, "Mission Success Starts with Safety," links to the "Risk Status W eb," which presents one such system. ${ }^{12}$ The system is a circle: identify, analyze, plan, track, control, and back to identify. The circle is centered on the words communicate and document.

Implementing a system-based approach for minimizing risk and reducing errors requires energy and a large up-front commitment. To ease the implementation, NASA uses a "Continuous Risk Management Roadmap" as a guide. In addition, relevant documents and resources such as a "System Risk-Management Database" and hard-copy risk-management texts are available. Examples of risk-management tools are presented (see Figure 1, above). If risk is defined as a combination of the possibility of a negative event or a failure and the consequences of the event or failure, then the risk can be given order using a risk matrix where the potential risk is a function of the severity of the event outcome and likelihood of the event occurring. ${ }^{12}$

W ith a roadmap in hand and resources for support, participants in a risk-reduction or error-prevention program are ready to begin. One plan promoted at NASA Glenn Research Center is the identify, analyze, plan, mitigate, track cycle, the phases of which are:
- Identify a risk and name it.

- Analyze the risk severity using a risk matrix. If the risk is low, stop the risk-analysis process. If the risk is high, continue.

- Plan a process for reducing or eliminating the risk.

- Mitigate the risk by following the risk-reduction process. If necessary, go back to the plan step to develop a new process. If the process works, analyze the level of risk reduction. Develop a new process if a greater reduction is needed.

- Track the risk to ensure that it remains at acceptable levels. If the risk increases, begin the cycle again.

Another risk-management tool that has promise in health care is a quality tool called Failure Mode and Effect Analysis (FMEA). It is a technique used to ensure that all reasonably conceivable failures will be uneventful. ${ }^{14}$ The FMEA analysis was developed to investigate problems or "negative quality" and is usually used in the planning or early design phases of new products or systems. However, at times, FMEA and a related technique, Failure Mode and Effects Criticality Analysis (FMECA) are used to decrease the impact of systems maintenance. ${ }^{15}$

When FMEA is applied to a new design or process, critical thinking is encouraged. Early in the development and planning stages of a product or process, participants in the analysis are encouraged to predict what parts of the product or process might go wrong or fail. They are also asked to consider how badly the product or process might go wrong, and what should be done to prevent the failure. In industry, cross-functional teams of engineers might work together on these analyses. Failure Modes Effect Analysis teams:

- Analyze the function and scope of the product or process.

- Identify areas for potential failure, defining the effects of the potential failure (when applicable), including frequency and severity, and determining the cause of the potential failure (when applicable).

- Prioritize the potential failures based on cost, safety, quality, and other attributes.

- Determine detection methods and corrective actions, and when risks arehigh, develop a control or back-up system or plan.

- Observe while maintaining and updating the analysis and control plan.

- Document the process for wide distribution and use..$^{14,16}$

Once again, this analysis is designed to answer the questions, "What can go wrong?" and "How bad can it be?" The similarity between FMEA and the "Identify, Analyze, Plan, Track, Control" system circle from NASA is striking. This is not surprising since FMEA has its roots in an early military quality-control process, and quality programs, by design, are intended to identify, analyze, plan, and implement improvement actions through a continuously cycling process. Under the right conditions, with management and employee support, either of these programs has the potential to be an effective error-reduction tool in health care. However, in nonhealth care settings, several lessons on quality programs have already been learned. These lessons may also be helpful in health 


\begin{tabular}{|c|c|c|c|c|c|c|c|c|}
\hline & $\begin{array}{c}\text { Factor/ Root } \\
\text { Cause }\end{array}$ & $\begin{array}{l}\text { Corrective } \\
\text { Actions }\end{array}$ & $\begin{array}{c}\text { Person } \\
\text { Assigned to: }\end{array}$ & $\begin{array}{c}\text { Completion } \\
\text { Date }\end{array}$ & $\begin{array}{l}\text { Completion } \\
\text { Indicator }\end{array}$ & $\begin{array}{c}\text { Completion } \\
\text { Sign-off }\end{array}$ & $\begin{array}{l}\text { Follow-up } \\
\text { Plans }\end{array}$ & $\begin{array}{c}\text { Follow-up } \\
\text { Dates }\end{array}$ \\
\hline \multicolumn{9}{|l|}{ Item 1} \\
\hline \multicolumn{9}{|l|}{ Item 2} \\
\hline \multicolumn{9}{|l|}{ Item 3} \\
\hline Item 4 & & & & & & & & \\
\hline
\end{tabular}

Sources: Root Cause Analysis and Accurate Assessment. Conducting a cost-effective root cause analysis. M edical Risk Management Associates, LLC (M RM A, LLC), 2000, available at http://sentinel-event.com/costeffective.htm; and Joint Commission on Accreditation of Healthcare 0 rganizations. Sentinel Events. 2000; JCAHO, available online at www.jcaho.org/sentinel/sentevnt_main.html.

care settings. They are:

1. Quality must be defined by the consumer.

2. Systems are responsible for errors.

3. Long-lasting internal and external partnerships are essential.

4. Appropriate and accurate data for analyses is vital.

5. Improvement does not occur in a vacuum.

6. Collaboration is the basis of teamwork.

7. Leadership for the improvement process must be developed.

8. Employees and management must be involved from beginning to end.

9. Strategic planning is imperative.

10. Long-lasting improvement occurs incrementally. ${ }^{17}$

\section{Error-Analysis Programs}

Sometimes, even in the presence of excellent risk-management and quality-improvement programs, something still goes wrong. And, if that something is large enough and a serious error occurs, it is important to find out why the error occurred and what can be done to prevent another similar error. But looking behind the scenes to identify the source of a problem can be an expensive, time-consuming, frustrating ordeal. The ordeal can be doubly difficult if the process or people involved are not familiar to the investigator. To help visualize a few of the difficulties in determining the underlying causes of errors in health care, try remembering back to when you were young. Did you ever walk into a dark room, flip the switch, and find that nothing happened? It was probably startling. Since your knowledge of electrical circuitry was limited, you probably immediately blamed the lamp or the switch; you were focused on the proximal cause of the problem. As you got older, you might have learned a little more about electricity and electrical circuits. If a light would not come on, even after you replaced the bulb, you probably went looking for the fuse or circuit box. You were considering a larger problem-a system problem. If replacing the fuse or flipping the breaker did not fix it, it was time to think globally. Maybe the lack of light was related to a bigger issue; maybe the power company was having trouble at the plant. If so, this was the source of the problem or the root cause. ${ }^{18}$ Locating the source of the problem- the root cause- is the intent of root-cause analysis.

Applying root-cause analysis requires a broad knowledge of the system and the events leading up to a problem or error. In the absence of a thorough understanding of the cause-and-effect relationship between the problems and symptoms, determining the root causes of the problems will be almost impossible. In health care, when considering inpatient care or outpatient treatments such as dialysis, hundreds or even thousands of events occur in the course of a single day of patient care. Each event can result in an error; each event can "fail to achieve what should be done." Many of these errors or failures, much like the failure of the lamp to produce light, can be the result of any one of a number of problems. Root-cause analysis can help to uncover the underlying problems, rather than simply lay blame on the most convenient cause.

Analyzing systems-based cause-and-effect relationships is the heart of root-cause analysis. ${ }^{19}$ The basic premise is that altering a proximal cause such as changing a light bulb may not solve the problem, and if the reason the light bulb burned out was a short in a circuit (i.e., a system problem), changing the bulb would not result in a long-term solution. To get an effective long-term solution, the circuit/root cause must be identified and addressed. But in health care, before a root cause can be identified, the organization must know that the intent is to locate the true cause(s) rather than a contributing cause. And members or employees of the organization must know which errors to report and when, how, and to whom to report the errors.

Root-cause analyses are usually conducted on sentinel events. However, depending on the organization's needs, they may also be conducted on nonsentinel events. When an event is reported and the decision is made to perform a root-cause analysis, one process that can be followed is to assemble an analysis team, gather relevant equipment and data, and analyze 
Quality Improvement, Risk Management, and Patient Education: Tools to Reduce Medication Error

\begin{tabular}{l|l}
\hline \multicolumn{2}{|c}{ Necessary Conditions for Success of the Ideal Medication-Use System } \\
\hline Members of the Health Care Community & Actions Required \\
\hline Patients & Assume some responsibility for health and medication goals \\
\hline Providers, payors, patients, and the pharmaceutical industry & Must be involved, understand, and support the system \\
\hline Health care providers & Cooperative collaboration \\
\hline Source: Re-engineering the medication use system: An interdisciplinary conference. Am J Health Syst Pharm 2000; 57: 537-601. \\
\hline
\end{tabular}

the relevant material to determine contributing factors and finally the root cause(s). The team usually consists of a facilitator who is in charge of the analysis and is experienced in rootcause analysis, a team leader who is an expert in the topics surrounding the event, an inclusive and multidisciplinary group of people involved with the event, and others from the department.

\section{Root-Cause Analysis}

1. As the analysis begins, the facilitator and team leader determine what equipment and information is available and what needs to be gathered and protected. ${ }^{19}$

2. Each member of the team independently records events leading to the error, including the circumstances of the error and events that followed the error or actions that were taken because of the error.

3. In a series of meetings, the team develops a complete sequence of events and identifies all corrective actions taken. The team should consider the activity in which the event occurred and human, equipment, environmental, and external factors. ${ }^{20}$ They should also consider checks and balances or barriers that should or could have prevented the error. After reviewing each factor and condition, they should identify the ones that may have contributed to the error.

4. The list of contributing events, conditions, or barriers is organized into logical sequences or groupings for further analysis. The sequences or groupings can be used to develop a flowchart of the events and conditions that might have contributed to the error.

5. The team reviews, rearranges, and, if necessary, alters the chart to determine how or why a sequence of events or grouping might have contributed to the error. Additional data should be gathered and reference texts and articles should be consulted as needed. By consensus, the team should designate each sequence or grouping as contributory or noncontributory. Contributing factor(s) that do not have future contributing factors are identified as root cause(s) of the event. ${ }^{19}$ Ideally, the team should have time to ponder the flowchart and revise it if needed.

6. If the team has reached consensus, corrective actions are identified, and a report is generated. The report will usually contain a table that details the team's findings and suggestions. This table is sometimes called an action plan (see Figure 2, page 159).

7. If the team is still in consensus after reviewing the action plan, the report is distributed as appropriate and the corrective process begins.

\section{- Actions for Pharmacy}

All sections of the health care system should be cultivating systems-based actions to improve quality, reduce risk, and predict and prevent errors. But in addition to these programs the Institute of Medicine and a host of state, federal, and independent organizations and individuals have made specific suggestions for reducing medical and medication errors. ${ }^{21,22}$ From this growing body of literature, there appears to be a consensus. Pharmacy needs to make some internal changes to improve quality, consistency, safety, and the error-free rate; but pharmacy also must work with payors, administrators, providers, support staff, and others using qualityimprovement and error-reduction tools to develop processes that will identify and predict system errors and root causes of actual and potential events. Organizations such as the National Coordinating Council for Medication Error Reporting and Prevention have also made recommendations that can help move these processes along, but each facility will need to develop processes that will work in its own environment at costs that will allow the facility to continue to operate. ${ }^{23-26}$

The report of a recent interdisciplinary conference on medication error presented the results of a workshop during which participants were asked to identify medication-use system (MUS) problems, identify characteristics of an ideal MUS, and provide a list of conditions required for the success of the ideal MUS. ${ }^{22}$ The problems list included issues related to organizational, social, professional, environmental, technological, economic and patient-specific problems. Features of the participants' ideal system included:

- a system designed by patients to meet the needs of patients;

- adequate, integrated, useful technology;

- adequate preparation, tracking, and storage facilities for medications;

- appropriate patient management with built-in performance measures; and

- balance between quality, access, and cost of care supported by research and evaluation using continuous quality improvement (CQI). 
Proposals for Improving Safety in the Medication-Use System

\begin{tabular}{|c|c|}
\hline Proposed Systems Changes & Proposed Actions for Pharmacists \\
\hline Computerized prescriber order entry & Be a safety advocate. \\
\hline Bar coding to identify medications & If it "feels" wrong, it may be wrong- ask for clarification. \\
\hline Unit-of-use packaging & $\begin{array}{l}\text { Double-check doses, entered orders, and calculations against } \\
\text { originals. }\end{array}$ \\
\hline Performance benchmarks and standardization of processes & $\begin{array}{l}\text { Check sound-alikes, look-alikes, decimal points, abbreviations, and } \\
\text { unique or special protocols. }\end{array}$ \\
\hline Match jobs with strengths (jobs matching psychological profile) & Do not ignore warnings, alerts, or stop orders. \\
\hline Simplify tasks to reduce dependence on individual skills & Know about patient allergies and previous adverse reactions. \\
\hline $\begin{array}{l}\text { Electronic dispensing linked to drug-use review and } \\
\text { pharmacist interventions }\end{array}$ & $\begin{array}{l}\text { Develop a systematic process for taking verbal prescriptions and } \\
\text { reviewing prescriptions/orders. }\end{array}$ \\
\hline Establish processes for error recovery & $\begin{array}{l}\text { Develop error-reducing work patterns and know your limits and the } \\
\text { limits of the system. }\end{array}$ \\
\hline Educate patients & $\begin{array}{l}\text { Keep up with professional and clinical knowledge and learn how to } \\
\text { use appropriate references. }\end{array}$ \\
\hline $\begin{array}{l}\text { Use of technology to improve information at point-of-care and serv- } \\
\text { ices to remote locations }\end{array}$ & $\begin{array}{l}\text { Counsel patients and provide drug information specifically for } \\
\text { patients. }\end{array}$ \\
\hline
\end{tabular}

The report specified three necessary conditions for the success of the ideal system (see Table 2, above). Interestingly, the list of conditions included almost all sectors of the health care community and used verbs such as understand and support. Although conditions in today's health care system may not accommodate an entirely new MUS, a number of recommendations have been made that contract pharmacies and pharmacists can implement in the short term (see Table 3, above).

\section{Member-Education Programs}

The last time you bought a new car, did you take it back to have a few little things fixed? The last time you traveled on a major airline, was the trip flawless? The opportunities for error are so plentiful that even when appropriate quality tools are used, errors slip through the system. In fact, in some industries economic constraints require that some errors- usually ones that are difficult to predict, do not occur with great frequency, and are not missioncritical-are acceptable. In the direct-patient-care component of health care, it is difficult to describe an error that is not mission-critical. Avoiding medication errors is part of maintaining good health. However, even when the health care system uses the right quality tools and has appropriate follow-up to previous errors, protecting a single patient from medication errors can be difficult. Protecting two million patients enrolled in a managed care plan from medication errors can seem impossible. There are too many opportunities for error and too few health professionals.

There is, however, another option. Patients can be empowered to become active participants in their own health care, to be responsible for asking questions, and, to some degree, to be accountable for doing what is needed to maintain good health and prevent medication errors. That is part of the idea behind by the SMART (Senior Medication Awareness Training) Coalition of California, a grass-roots organization founded four years ago by two senior citizens after hearing of the potential problems within our medical system, the impact of the problems on patients, and the $\$ 76$ billion price tag. ${ }^{27,28}$

Coalition members recruit senior citizens and senior organizations and train them or their members to present information on medication errors and error prevention. Trained volunteers, mostly senior citizens, present the coalition's program at senior centers, churches, and almost anywhere they are invited, as long as senior citizens are there. The program has been adopted by a retired 
teachers' organization, several state agencies, a nationwide health care organization, and, most recently, a nationwide association for retired persons.

The program presentation is designed to take about one hour to complete. After a brief introduction and explanation of the program, participants learn about the significance of medication-related problems, watch a short videotape entitled "To Lead a Better Life," and learn helpful medication tips and five key questions or actions that can help protect them from medication errors. ${ }^{29}$ There are also medication tips that instruct seniors to make sure that they understand the directions for taking their medications, to take their medication exactly as directed, to ask what to do if they forget to take a dose and not to share medications, and give a variety of other helpful medication tips.

Seniors are also instructed to tell all of their health care providers what medications they are taking and what health problems they have. To aid seniors in this effort, program participants receive a SMART card. The card folds into a credit-card-size case and has areas for basic information such as name, address, physicians' names, vaccination information, emergency contact information, and medical problems. The heart of the card is a section in which to record medication names, doses, directions, comments, and a listing of the five key questions or actions:

-W hat is the name of this medication, and what is it supposed to do?

- How and when do I take it, and for how long?

-What food, drink, and other medications and activities should I avoid while taking this medication?

- Are there any side effects, and what do I do if one occurs?

- Be sure to inform your pharmacist and physician of any other medications, including over-the-counter products and herbals you are currently taking and any allergies you may have to particular medications.

The coalition's program has been presented to more than 8,000 seniors. The program has some evidence of success: $82 \%$ of participants in a pilot study stated that after completing the one-hour training program, they would be more likely to ask questions of health care providers. The coalition is planning a study to determine whether the program is effective in reducing medicationrelated problems and the cost of care.

The Agency for Healthcare Research and Quality (AHRQ) also provides information for patients on medical and medication errors. ${ }^{30}$ Their publication, "A Patient Fact Sheet: 20 Tips to Help Prevent Medical Errors," explains the significance of medical errors and where they can occur. It emphasizes that errors can happen when doctors and patients have trouble communicating. The first helpful tip is "The single most important way you can help to pre vent error is to be an active member of your health care team." A few of the other hints listed under the heading "M edicines" include: -When your doctor writes you a prescription, make sure you can read it.
- Ask for information about your medications in terms you can understand-both when your medicines are prescribed and when you receive them.

- When you pick up your medicine from the pharmacy, ask: Is this the medicine that my doctor prescribed?

- If you have any questions about the directions on your medicine labels, ask.

- Ask your pharmacist for the best device to measure your liquid medicine. Also, ask questions if you're not sure you know how to use it.

- Ask for written information about the side effects your medication could cause.

The AHRQ document also provides tips and questions for reducing errors during hospital stays and surgery and other steps patients can take to help ensure error-free care.

Similarly, other publications have presented recommendations to help patients use medications safely. All of the lists of hints and programs instruct patients to let providers know if they have a problem, but one goes a little further and also instructs patients to: - inform their caregivers about the positive effects of medications;

- check with their pharmacist if the appearance of their medication has changed;

- keep medications in the original vial;

- find out if it is acceptable to break, chew, or mix medications;

- keep their medications away from their pets' and other medications and other chemicals; and

- reminds women that if they are pregnant or breast-feeding they should inform their health care providers before taking any medication. ${ }^{31}$

Overall, the ideas and the support for helping patients help themselves and for making patients informed members of the health care team is growing. But many patients will still need to be informed, be trained, and receive tools before they can be reliable members of the team

\section{- Conclusion}

The level of risk from medication errors depends on the medication and the type of error. However, in general, the risk potential is high. The potential severity of an error can be devastating, and under the current medication-use system the likelihood of an error is probable, even though the frequency may be rare. In the interest of patient safety, MCOs and their contracted health care providers need to develop plans and programs to: (1) reduce or eliminate the risk of errors, (2) mitigate the risk following the planned risk reduction process, and (3) follow up to ensure the effectiveness of the process. In addition to having error-reduction programs, health care organizations must analyze errors that occur, and those that are prevented, to uncover the root cause of the error or potential error. Then, using programs much like those used for quality assurance and risk reduction, actions to change the system surrounding the error should be taken. 


\section{Quality Improvement, Risk Management, and Patient Education: Tools to Reduce Medication Error}

Overall, to reduce the risk of medication errors in their covered populations, MCOs can:

- develop system-based programs for in-house use,

- selectively contract with companies with risk-reduction systems in place,

- provide programs to providers of care to help them adopt or develop their own systems-based program, and

- provide education programs to members.

The consistent and effective use of quality assurance, risk management, and patient-education tools can help each member of the managed care community participate in risk reduction and quality improvement and ultimately reduce the toll of medication errors.

\section{References}

1. Kohn LT, Corrigan JM, Donaldson MS, eds. To err is human. Building a safer health system. Committee on Quality of Health Care in America. Institute of Medicine. Washington National Academy Press, 1999.

2. Agency for Healthcare Research and Quality. Reducing errors in health care. Translating research into practice. AHRQ Publication No. 00-P058, April 2000; Rockville, MD: AHRQ, available online at www.ahrq.gov/research/errors.htm.

3. Agency for Healthcare Research and Quality. Medical Errors: The scope of the problem. Fact sheet, Publication No. AHRQ 00-P037, February 2000. Rockville, MD: AHRQ, available online at www.ahrq.gov/qual/errback.htm.

4. Agency for Healthcare Research and Quality. Statement on medical errors. John M. Eisenberg, M.D., Director, Agency for Healthcare Research and Quality, before the Senate Appropriations Subcommittee on Labor, Health and Human Services, and Education, December 13, 1999, Washington DC. Rockville, MD: AHQR, available online at www.ahrq.gov/news/stat1213.htm.

5. Porter J, Jick H. Drug-related deaths among medical inpatients. JAMA 1977; 237: 879-81.

6. Bates DW et al. Incidence of adverse drug events and potential adverse drug events: Implications for prevention. ADE Prevention Study Group. JAMA 1995; 274: 29-34.

7. Norton LL. Medical and medication errors, their impact and proposals forchange: a partial summary of reports by the Institute of Medicine and the Quality Interagency Coordination Task Force. J Managed Care Pharm 2001; 7: 62-68.

8. Burman JF. Preventability of adverse drug reactions. Ann Intern Med 1976; 85: $80-81$.

9. International Organization for Standards. Introduction to ISO. ISO, 1999. Available online at www.iso.ch/infoe/intro.htm.

10. NASA. Continuous risk management. Software Assurance Technology Center, 2000. Available online at http://satc.gsfc.nasa.gov/crm/information/index.htm.

11. Tokarski C. Setting a research agenda on medical errors. Medscape, 2000. Available online at www.medscape.com/medscape/M oneyM edicine/journal/2000/v01.n05/mm0925.ahrq/mm0925.ahrq.html.

12. NASA/Glenn Research Center Risk Management Office. Risk status web. NASA/Glenn Research Center, 2000. Available online at http://tkurtz.grc.nasa.gov/riskstatus.

13. NASA/Glenn Research Center Office of Safety and Assurance Technologies. NASA/Glenn Research Center Office of Safety and Assurance Technologies (OSAT), 2000. Available online at http://osat.grc.nasa.gov.

14. Anonymous. FMEA: Failure mode and effect analysis. Available online at www.tm.tue.nl/race/ce/fmea_2htm.

15. Anonymous. FMECA introduction. Available online at www.pmaint.com/index.html/index.html/EFMECA.htm.

16. Robb Wilcox. Risk-informed regulation of marine systems using FMEA. U.S. Coast Guard Marine Safety Center. Washington. Available online at www.uscg.mil/hq/msc/fmea.htm.

17. Hatten R, Knapp D, Salonga R. Action research: Comparison with the concepts of "The reflective practitioner" and "Quality Assurance." Ian Hughes, The University of Sydney, 1998. Available online at www.scu.edu.au/schools/gcm/ar/arr/arow/rdr.htm.

18. System Management Arts (SMARTs). Root cause analysis and its role in event management. Publications and Communications Inc. (PCI), 2000.

Available online at www.ciscoworldmagazine.com/whitepap/smarts.htm .

19. Root Cause Analysis and Accurate Assessment. Conducting a cost-effective root cause analysis. Medical Risk Management Associates, LLC. (MRMA, LLC), 2000. Available http://sentinel-event.com/costeffective.htm.

20. Joint Commission on Accreditation of Healthcare Organizations. Sentinel Events. 2000; JCAHO, available online at www.jcaho.org/sentinel/sentevnt_main.html.

21. Understanding and preventing drug misadventures. A multidisciplinary conference sponsored by the ASHP Research and Education Foundation in cooperation with the American Medical Association, the American Nursing Association, and the American Society of Hospital Pharmacists. Am J Health Syst Pharm. 1995; 52; 369-416.

22. Re-engineering the medication use system: An interdisciplinary conference. Am J Health Syst Pharm. 2000; 57: 537-601.

23. National Coordinating Council for Medication Error Reporting and Prevention. Recommendations to reduce errors related to administration of drugs. June 1999; Rockville, MD: USP, available online at www.nccmerp.org/rec_990629.htm.

24. National Coordinating Council for Medication Error Reporting and Prevention. Recommendations for avoiding error-prone aspects of dispensing medications. March 1999; Rockville, MD: USP, available online at www.nccmerp.org/rec_990319.htm.

25. National Coordinating Council for Medication Error Reporting and Prevention. Recommendations to health care organizations to reduce errors due to labeling and packaging of drug products and related devices. March 1998; Rockville, MD: USP, available online at www.nccmerp.org/rec_980717.htm.

26. National Coordinating Council for Medication Error Reporting and Prevention. Recommendations to correct error-prone aspects of prescription writing. September 1996; Rockville, MD: USP, available online at www.nccmerp.org/rec_960904.htm.

27. SMART Coalition of California. Senior Medication Awareness Training (SMART): Consumer information for older Americans. November 2000; Sacramento, CA: SMART Coalition, available March 2001 online at http://www.smartcoalition.org.

28. Johnson JA, Bootman JL. Drug-related morbidity and mortality. A cost-ofillness model. Arch Intern Med 1995; 155: 1949-56.

29. Glaxo Wellcome, Inc. To lead a better life. Videotape, 1995.

30. Agency for Healthcare Research and Quality. 20 tips to help prevent medical errors. Patient fact sheet. AHRQ Publication No. 00-PO38, February 2000; Rockville, MD: AHRQ, available online at

www.ahrq.gov/consumer/20tips.htm.

31. Lesar TS. Recommendations for reducing medication errors. Medscape Pharmacist, 2000. Available online at www.medscape.com/medscape/pharmacists/journal/2000/v01.n04/mph7175.lesa/mph7175.lesa-01.html. 


\section{E E X A M}

Quality Improvement, Risk Management, and Patient Education: Tools to Reduce Medication Error

Upon completion of this continuing education program, participants will be able to:

1. Explain the purpose of accreditation and accreditation standards and their limitation.

2. Differentiate quality, consistency, and safety.

3. Discuss tools for assuring quality and predicting failure within systems.

4. Describe a process for conducting a root cause analysis.

5. Discuss actions pharmacy and pharmacists can take to reduce medication errors.

6. List steps that patients can take to help prevent medication errors.

\section{SELF-ASSESSMENT QUESTIONS}

1. The number of deaths attributable to preventable medication errors has been estimated to be:
a. 7,000 per year.
b. $44,000-98,000$ per year.
c. 70,000 per year.
d. none of the above.

2. Accreditation:

a. provides a guarantee of safety.

b. is limited to organizations with $100 \%$ error-free care.

c. is defined as conferring approval or recognition for conforming to standards.

d. None of the above

3. ISO 9000, PDCA, and FMEA are all:

a. acronyms for projects at NASA.

b. tools for quality improvement or risk management.

c. based on systems developed by the military.

$d$. all of the above.
4. Risk can be managed in environments that do all of the following except:

a. prioritize risk.

b. perform research to increase the understanding of risk.

c. implement strategies to mitigate risk.

d. assess risk on a semi-annual basis.

5. Risk-matrix design is based on:

a. event severity and likelihood of occurrence.

b. corrective mechanisms and cost.

c. attributes and strategies.

$d$. none of the above.

6. FMEA was developed and is used:

a. exclusively for design analysis to eliminate negative quality.

b. exclusively for maintenance to document exceptional quality.

c. primarily for maintenance to locate negative quality.

d. primarily for design analysis, but can be used in systems maintenance.

7. Root-cause analysis is designed to locate the true cause of sentinel events so that the responsible individuals can be punished.

a. True

b. False

8. At the completion of a root-cause analysis, an action plan is developed that can be designed to document:

a. corrective actions, follow-up plans, and follow-up dates.

b. completion date, completion indicator, and completion sign-off analysis.

c. root cause and the person assigned to oversee the corrective actions.

d. all of the above
9. The basic idea behind the SMART

Coalition training program is:

a. patients can be empowered to become active participants in their own health care.

b. physicians and pharmacists should provide no-cost and low-cost care to seniors.

c. senior volunteers should provide brown bag and medication-review sessions.

d. none of the above.

10. Based on information from a multidisciplinary conference, conditions that are necessary for the success of "the ideal" medication-use system are:

a. patients assuming some responsibility for health and medication goals.

b. health care providers working in cooperative collaboration.

c. both $a$ and $b$.

d. none of the above. 
DEMOGRAPHIC INFORMATION (not for scoring)

11. In what type of setting do you work? (Leave blank if none of the responses below applies.)
a. $\mathrm{HMO}$
b. PPO
c. Indemnity insurance
d. Pharmacy benefits management
e. Other

12. Did this program achieve its educational objectives?
a. Yes
b. No

13. How many minutes did it take you to complete this program, including the quiz? (Fill in on answer sheet.)
14. Did this program provide insights relevant or practical for you or your work?
a. Yes
b. No

15. Please rate the quality of this $C E$ article.
a. Excellent
c. Fair
b. Good
d. Poor

\section{INSTRUCTIONS}

$\mathrm{PE}$ This test affords 1 hour ( $0.10 \mathrm{CEU}$ ) of continuing pharmaceutical education in all states that recognize the American Council on Pharmaceutical Education. To receive credit, you must score at least $70 \%$ of your test answers correctly. To record an answer, darken the appropriate block below. Mail your completed answer sheet to: Academy of Managed Care Pharmacy, 100 N. Pitt Street, Suite 400, Alexandria, VA 22314. If you score 70\% or more, a certificate of achievement will be mailed to you within eight weeks. If you fail to achieve $70 \%$ on your first try, you will be allowed only one retake. The ACPE Provider Number for this lesson is 233-000-01-002-H04. This offer of continuing education credit expires April 30, 2002.
A B C D

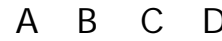
11. $\square \mathrm{A} \quad \square \mathrm{B} \quad \square \mathrm{C} \quad \square \mathrm{D} \quad \square \mathrm{E}$
1. $\square \quad \square \quad \square \quad \square$
2. $\square \square \square \quad \square$
3. $\square \square \square \quad \square$
4. $\square \quad \square \quad \square \quad \square$
5
6. $\square \square \square \square$
7. $\square \quad \square \quad \square \quad \square$
8. $\square \square \square \square$
9. $\square \quad \square \quad \square \quad \square$
10.
12. $\square$ Yes $\square$ No
13. Minutes
14. $\square$ Yes $\square$ No
15. $\square \mathrm{A} \quad \square \mathrm{B} \quad \square \mathrm{C} \quad \square \mathrm{D}$

Participant Identification: Please type or print.

Date:

Social Security \#:

Work Phone \#

For Identification Purposes Only

Name:

LAST FIRST MIDDLE

Company:

Address:

$\begin{array}{llll}\text { STREET (with Apt. No.) or P.O. Box } & \text { CITY } & \text { STATE } & \text { ZIP }\end{array}$

State \& Lic. No.:

STATE LICENSE NO.

Member Type: $\square$ Active $\square$ Supporting Associate $\square$ Student $\square$ Nonmember 